\title{
Evaluation of antidepressant effects of hydroalcoholic extract of Kelussia odoratissima Mozaffarian in male mice
}

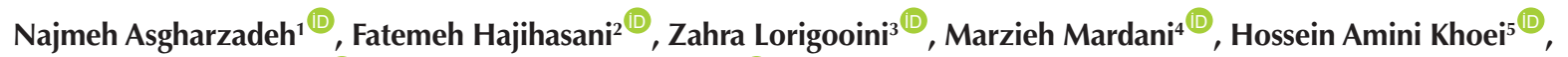 \\ Mohamadtaghi Moradi $^{(\mathbb{D}}{ }^{,}$Mehrdad Shahrani Korrani $^{* *}$
}

${ }^{1}$ MSc of Physiology, Shahrekord University of Medical Sciences, Shahrekord, Iran ${ }^{2}$ Medical Student, Student Research Committee, Shahrekord University of Medical Sciences, Shahrekord, Iran ${ }^{3}$ Assistant Professor of Pharmacognosy, Shahrekord University of Medical Sciences, Shahrekord, Iran

${ }^{4}$ Assistant Professor of Anatomy, Shahrekord University of Medical Sciences, Shahrekord, Iran

${ }^{5}$ Assistant Professor of Pharmacology, Shahrekord University of Medical Sciences, Shahrekord, Iran

${ }^{6}$ Assistant Professor of Virology, Shahrekord University of Medical Sciences, Shahrekord, Iran

${ }^{7}$ Assistant Professor of Physiology, Shahrekord University of Medical Sciences, Shahrekord, Iran

*Corresponding Author: Mehrdad Shahrani Korrani, Department of Physiology, Shahrekord University of Medical Sciences, Shahrekord, Iran. Tel: +989131856077, Email: mehrdadeshahrani20000@yahoo.com

\begin{abstract}
Background and aims: Depression is one of the most common psychiatric disorders with serious impacts on individuals, and is often associated with physiological symptoms. In this study, we investigated the antidepressant effects of Kelussia odoratissima Mozaffarian extract in male mice. Methods: A total of 56 male mice (weight: 25-35 g; age: 6-8 weeks) were used. K. odoratissima Mozaffarian hydroalcoholic extract was prepared by maceration method. The forced swim test, open field test, and splash test were used to investigate the antidepressant effects. The mice were assigned into eight equal groups ( $\mathrm{n}=7$ each) as follows: receiving 25, 50, 75, and $100 \mathrm{mg} / \mathrm{kg}$ of $K$. odoratissima Mozaffarian extract; receiving $5 \mathrm{mg} / \mathrm{kg}$ reserpine; receiving $5 \mathrm{mg} / \mathrm{kg}$ reserpine along with $20 \mathrm{mg}$ fluoxetine; and normal saline. All injections were done intraperitoneally for one week before the test. Malondialdehyde (MDA) levels and antioxidant capacity of serum and brain were also measured in all groups. Statistical analysis was performed by one-way ANOVA and Tukey's test.

Results: Extract of $K$. odoratissima Mozaffarian significantly decreased the immobility time in forced swim test $(P<0.001)$. The extract also significantly increased splash time and elapsed time in the open field test, which was statistically significant compared with reserpinated mice $(P<0.001)$. Reserpine increased MDA levels and decreased the antioxidant capacity of serum and brain, whereas hydroalcoholic extract of $K$. odoratissima decreased MDA dose-dependently and increased antioxidant capacity $(P<0.001)$.

Conclusion: The results of this study showed that hydroalcoholic extract of $K$. odoratissima has antidepressant effects, but further studies are necessary to investigate the involved mechanisms.

Keywords: Kelussia odoratissima, Depression, Flavonoids, Mice
\end{abstract}

Received: 23 June 2020, Accepted: 3 August 2020, ePublished: 30 March 2021

\section{Introduction}

Mood refers to inner feeling that influences behavior and understanding of the surrounding world environment. Mood can be low, high, or normal. Mood disorders include a wide range of mental illnesses, one of the most common of which is major depressive disorder (MDD) (1). The main features of MDD include low mood, pessimistic thinking, lack of pleasure, decreased strength, slowness, low self-esteem, loss of appetite and death or suicidal thoughts. depression symptoms including feeling empty and hopeless or pessimistic, feeling guilty, irritability and restlessness, decreased interest in activities or enjoyable pastimes. Unknown depression is a common cause of discomfort and a factor for delaying recovery from physical illness; it is therefore essential for all physicians to have the ability to diagnose this disorder, treat mild cases, and identify cases that require specialized care due to the risk of suicide (2).

Clinical experience has shown that patients with depression do not have appropriate adherence to using drugs due to side effects or fear of taking chemical drugs. In addition, some studies have shown that available drugs are effective in only half of the cases and occasionally have not provided a complete and appropriate response. Given that herbal medical plants are more economical than chemical treatments, this study aimed to investigate the effective herbal treatments for depression that have a higher effect than conventional drugs and fewer side effects.

In recent years, research to find herbal remedies as a complementary and even alternative drug for the treatment of depression has become particularly important. In this regard, the effectiveness of numerous plant extracts and

(C) 2021 The Author(s); Published by Shahrekord University of Medical Sciences. This is an open-access article distributed under the terms of the Creative Commons Attribution License (http://creativecommons.org/licenses/by/4.0), which permits unrestricted use, distribution, and reproduction in any medium, provided the original work is properly cited. 
fragrances against depression in animal models have been demonstrated in double-blind clinical trials (3-11). In 2003, Mozaffarian introduced the mountain celery belonging to the Apiaceae family, scientifically referred to as $K$. odoratissima Mozaffarian, as a species of the Kelussia genus $(12,13)$. Kelussia odoratissima is a plant with vertical, slightly thick roots and a hollow stem that reaches a height of one meter. Its growth period is from early March to late May (12). The plant is native to certain areas of Iran such as Chaharmahal and Bakhtiari, Isfahan, and Kohgiluyeh and Boyer-Ahmad. Its occurrence has not been reported in other parts of the world yet. In Persian, $K$. odoratissima is called Kelows (14). Research on the pharmacological properties of this plant has shown that it has analgesic, anti-inflammatory, sedative, hypotensive, hypoglycemic fibrinolytic, acid- and stomach pepsin-lowering, and memory boosting effects.

According to studies, this plant has flavonoids, phthalide compounds, fatty acids, and phenolic substances to which cancer preventing and hepatoprotective effects have been attributed.

Due to its phenolic and flavonoid compounds, this plant has also free radical-inhibiting and antioxidant effects, which can be compared with those of alpha-tocopherol and prevent the formation of fat plaques in the arteries (15-17). In recent years, medicinal plants have attracted the attention of researchers as natural, safe, and beneficial compounds for patients.

According to the evidence, no studies have yet been performed on the antidepressant effects of hydroalcoholic $K$. odoratissima extract, and given the presence of flavonoid compounds for the neuroprotective activity in plant extracts, it appears to be effective in treating depression. In the present study, we investigated the antidepressant effects of hydroalcoholic $K$. odoratissima extract.

\section{Materials and Methods}

In this experimental study, extraction was performed by maceration. For this purpose, the stems and leaves of $K$. odoratissima collected from Chaharmahal and Bakhtiari province, Iran were purchased from a local grocery in 2019. The quality and originality of the samples were confirmed in the Medical Plants Research Center of Shahrekord University of Medical Sciences, Iran. After pulverizing the samples with electric mill, we added the resulting powder in an appropriate amount to water (30\%) and methanol $97 \%$ (70\%). The resulting liquid was filtered 72 hours later by a Buchner funnel and extraction was done using a rotary evaporator. After the extract was dried in the incubator, the extract was shaved. Then, by dissolving an appropriate amount of extract in normal saline, the extract was prepared at concentrations of $25,50,75$, and $100 \mathrm{mg} /$ kg (13).

In this experimental study, 56 male mice weighing 25$35 \mathrm{~g}$ and aged 6-8 weeks were used in the Medicinal Plants
Center and Animal House of Shahrekord University of Medical Sciences between March and September, 2019.

The injection of normal saline, drug, or extract for all mice was done intraperitoneally at $1 \mathrm{ml} / \mathrm{kg}$ body weight.

\section{Measurement of serum/brain tissue antioxidant capacity}

Three solutions were used to measure serum antioxidant capacity, including buffer $(1.55 \mathrm{~mL}$ of acetate sodium and $8 \mathrm{~mL}$ of concentrated acetic acid to a final volume of 500 $\mathrm{ml}$ by addition of distilled water), $20 \mathrm{~mL}$ of chloride iron (III) to a final volume of $500 \mathrm{ml}$ by addition of distilled water, and a solution of triazine ( $47 \mathrm{mg}$ of triazine dissolved in $40 \mathrm{ml}$ of hydrochloric acid). Then, $25 \mu \mathrm{L}$ of sample was added to $1.5 \mathrm{~mL}$ of the stock solution and placed at $37^{\circ} \mathrm{C}$ for 10 minutes. Then, optical absorbance was read at 593 nm wavelength.

\section{Measurement of serum/brain malondialdebyde levels} Briefly, $0.5 \mathrm{~g}$ of thiobarbituric acid was mixed with $80 \mathrm{ml}$ of $20 \%$ acetic acid; its $\mathrm{pH}$ was adjusted to 3.5 by adding sodium hydroxide, and its volume was increased to $100 \mathrm{ml}$ by addition of $20 \%$ acetic acid. Next, $100 \mu \mathrm{L}$ of serum or homogeneous brain tissue sample was mixed with $100 \mu \mathrm{L}$ of SDS $1.8 \%$ solution and $2.5 \mathrm{~mL}$ of the sample solution. The samples were immersed in boiling water for one hour, then cooled and centrifuged at $4000 \mathrm{rpm}$. Optical absorbance of zinc solution was recorded at $523 \mathrm{~nm}$ (18).

\section{Investigations of depression \\ Forced swim test}

Forced swim test is one of the most common standard pharmacological animal models for estimating the antidepressant effects of various chemical and plant compounds in rodents. This method is sensitive to the effects of all antidepressants (19).

In this method, after injecting extracts or drugs, the mice were placed separately in glass cylinders $25 \mathrm{~cm}$ in height, $12 \mathrm{~cm}$ in diameter, containing water at $25^{\circ} \mathrm{C}$; conventionally, the time when hands and feet discontinue moving is regarded as the time of immobility. The entire test lasted 6 minutes, the first 2 minutes of which was specified for animal adaptation to the environment, and during the next 4 minutes, the duration of immobility and swimming was recorded in seconds by a stopwatch. Swimming was considered to be the movement of the animal's arms and legs and rotating around the cylinder (20).

\section{Open field test}

Open field test was used to investigate the exploring or motor activity $(21,22)$. In this test, the animal is placed in an unknown environment, the surrounding walls of which prevent the animal from escaping. Several versions of this test are currently available that differ in terms of 
shape, ambient lighting, or the presence of objects in the environment and other characteristics. The procedure is usually performed by placing a mouse or rat in the center or near the surrounding walls, and a variety of animal behaviors are recorded over 2-20 minutes.

To perform open field test, a square box made of fiberglass was used. At a distance of $8 \mathrm{~cm}$ from the bottom of the box, a green screen of the same material with dimensions of $100 \times 100 \mathrm{~cm}$ was installed. This page was divided into 25 equal squares, with 5 squares on each side of the box. In the center of each of the squares, as well as in the corners and in the middle of the sides of the middle squares, there were holes with a diameter of $3 \mathrm{~cm}$. After the last injection, the mice were separately placed in a box from one corner of the box, and behavioral factors were measured for 5 minutes. After each test, the box was cleaned with a cotton swab dipped in alcohol for the next mouse. The entrance to the box and the location and time were the same for all mice. The test was performed in a quiet environment illuminated by a fluorescent lamp located just above the box.

\section{Splash test}

Splash test has been approved for studying depression in rodents. In this test, 10\% sucrose solution was sprayed on the back of the animal, and the mouse's licking liquid was recorded in 5 minutes and statistically studied (23).

\section{Statistical analysis}

After collecting and entering the data in SPSS software version 17 , Shapiro-Wilk test was done to test the normality of data. Statistical analyses were performed using one-way ANOVA and Tukey's test, and $P<0.05$ was considered as significant level.

\section{Results}

The effect of intraperitoneal injection of four different concentrations of Kelussia odoratissima Mozaffarian extract $(25,50,75$, and $100 \mathrm{mg} / \mathrm{kg})$ on immobility time in mice

Intraperitoneal injection of reserpine at a dose of $5 \mathrm{mg} / \mathrm{kg}$ resulted in an increase in immobility time compared with the normal saline-receiving group $(P<0.001)$.

Intraperitoneal injection of $K$. odoratissima extract at $25,50,75$, and $100 \mathrm{mg} / \mathrm{kg}$ body weight resulted in a significant decrease in immobility time compared with the reserpinated group in the forced swim test, so that the difference was significant at $25 \mathrm{mg} / \mathrm{kg}(P<0.01)$ as well as at 50,75 , and $100 \mathrm{mg} / \mathrm{kg}$ body weight $(P<0.001)$ (Figure $1)$.

Fluoxetine at $20 \mathrm{mg} / \mathrm{kg}$ body weight also significantly reduced the duration of immobility compared with the group receiving reserpine alone, which is a good indication of the antidepressant effects of fluoxetine $(P<0.001)$ (Figure 1).
The effect of intraperitoneal injection of four different concentrations of Kelussia odoratissima Mozaffarian extract $(25,50,75$, and $100 \mathrm{mg} / \mathrm{kg})$ on the time spent by mice in the central part

Intraperitoneal injection of reserpine at $5 \mathrm{mg} / \mathrm{kg}$ resulted in a reduction in the time spent by the mice in the central part of the open field test compared with the group receiving normal saline $(P<0.001)$. Intraperitoneal injection of $K$. odoratissima extract at $25,50,75$, and $100 \mathrm{mg} / \mathrm{kg}$ body weight resulted in an increase in the time spent by mice in the central part compared with the group receiving reserpine in the open field test with the difference being statistically significant, so that at the concentration of $50 \mathrm{mg} / \mathrm{kg}$, the difference was significant $(P<0.05)$ as well as at 75 and $100 \mathrm{mg} / \mathrm{kg}$ body weight $(P<0.001)$. Moreover, fluoxetine at $20 \mathrm{mg} / \mathrm{kg}$ body weight resulted in a significant increase in the time spent in the central part compared with the group receiving reserpine alone $(P<0.001)$ (Figure 2).

The effect of intraperitoneal injection of four different concentrations of Kelussia odoratissima Mozaffarian extract $(25,50,75$, and $100 \mathrm{mg} / \mathrm{kg})$ on the licking time of mice

Intraperitoneal injection of reserpine at $5 \mathrm{mg} / \mathrm{kg}$ resulted in a reduction in licking time in the splash test compared with the group receiving normal saline $(P<0.001)$. Intraperitoneal injection of $K$. odoratissima extract at 25 , 50,75 , and $100 \mathrm{mg} / \mathrm{kg}$ body weight resulted in increased licking time compared with the reserpinated group in the open field test, and at only two doses of 75 and $100 \mathrm{mg} /$ $\mathrm{kg}$, the difference was statistically significant $(P<0.001$ and $P<0.05$, respectively).

Fluoxetine at $20 \mathrm{mg} / \mathrm{kg}$ body weight also resulted in a significant increase in licking time compared with the

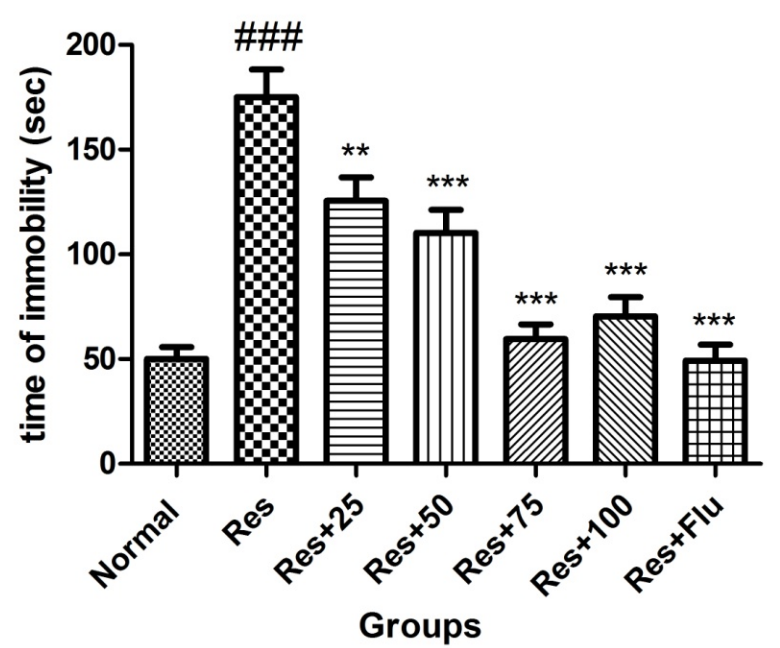

Figure 1. The effect of intraperitoneal injection of four different concentrations of $K$. odoratissima Mozaffarian extract $(25,50$, 75, and $100 \mathrm{mg} / \mathrm{kg}$ ) on immobility time in mice. Flu= Fluoxetine, Res=reserpine. ${ }^{\sharp} V s$. normal group $\left({ }^{\# \# ~} P<0.001\right)$, "Vs. reserpinereceiving group $\left({ }^{* *} P<0.01,{ }^{* * *} P<0.001\right)$ 


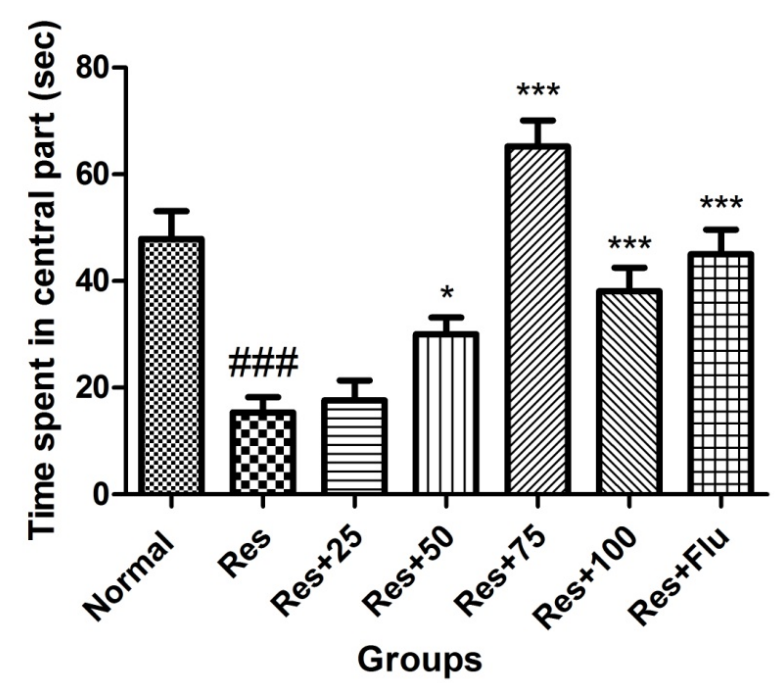

Figure 2. The effect of intraperitoneal injection of four different concentrations of Kelussia odoratissima Mozaffarian extract (25, 50, 75 and $100 \mathrm{mg} / \mathrm{kg}$ ) on the time spent by mice in the central part.

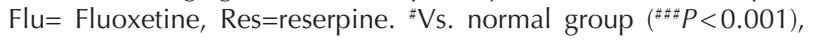
${ }^{*} \mathrm{~V}$ s. reserpine-receiving group $\left({ }^{*} P<0.05,{ }^{* * *} P<0.001\right)$.

group receiving reserpine alone $(P<0.001)$ (Figure 3$)$.

The effect of intraperitoneal injection of four different concentrations of Kelussia odoratissima Mozaffarian extract $(25,50,75$, and $100 \mathrm{mg} / \mathrm{kg}$ ) on the brain and serum malondialdebyde levels of mice

Intraperitoneal injection of reserpine at $5 \mathrm{mg} / \mathrm{kg}$ resulted in an increase in serum and brain malondialdehyde (MDA) levels in mice compared with the group receiving normal saline $(P<0.001)$.

Intraperitoneal injection of $K$. odoratissima extract at $25,50,75$, and $100 \mathrm{mg} / \mathrm{kg}$ body weight resulted in a decrease in serum and brain MDA levels compared with the reserpine-receiving group, with the difference being statistically significant, so that at $25 \mathrm{mg} / \mathrm{kg}$, the difference was significant at the significance level of $P<0.01$, and at 50,75 , and $100 \mathrm{mg} / \mathrm{kg}$ body weight, the difference was statistically significant at the significance level of $P<0.001$ level in serum and at $75 \mathrm{mg} / \mathrm{kg}$ at the significance level of $P<0.001$ level and at $100 \mathrm{mg} / \mathrm{kg}$ at the significance level of $P<0.05$ level in brain tissue, the difference was statistically significant.

Fluoxetine at $20 \mathrm{mg} / \mathrm{kg}$ body weight also significantly reduced MDA levels in brain tissue and serum in mice compared with the group receiving reserpine alone $(P<0.001)$ (Figure 4).

Effects of intraperitoneal injection of four different concentrations of Kelussia odoratissima Mozaffarian extract (25, 50, 75 and $100 \mathrm{mg} / \mathrm{kg}$ ) on serum and brain antioxidant capacity in mice

Intraperitoneal injection of reserpine at $5 \mathrm{mg} / \mathrm{kg}$ resulted in an increase in serum and brain MDA levels in mice compared with the group receiving normal saline
$(P<0.001)$.

Intraperitoneal injection of $K$. odoratissima extract at 25 , 50,75 , and $100 \mathrm{mg} / \mathrm{kg}$ body weight resulted in a decrease in serum and brain MDA levels compared with the group receiving reserpine with the difference being statistically significant, so that at $75 \mathrm{mg} / \mathrm{kg}$, the difference was statistically significant at the significance level of $P<0.001$, and at $100 \mathrm{mg} / \mathrm{kg}$ body weight, the difference was statistically significant at the significance level of $P<0.01$ level in serum and at $50 \mathrm{mg} / \mathrm{kg}$ at the significance level of $P<0.05$ and at 75 and $100 \mathrm{mg} / \mathrm{kg}$ at the significance level of $P<0.001$, the difference was statistically significant in brain tissue.

Fluoxetine at $20 \mathrm{mg} / \mathrm{kg}$ body weight also significantly reduced MDA levels in brain tissue and serum in mice compared with the group receiving reserpine alone $(P<0.001)$ (Figure 5).

\section{Discussion}

It has been observed that reserpine injection in mice is associated with a significant increase in immobility in the forced swim test, which is in line with the findings of Petit-Demouliere et al in 2016 (19).

In the present study, open field test was used to evaluate the exploring activity, depression, and anxiety in mice, and it was observed that reserpine injection in the mice was associated with significant reduction in the frequency of rearing and grooming behavior compared with control group mice. Angrini and colleagues' study on reserpinated mice showed a significant reduction in rearing and grooming behavior in the open field test (24). In a 2014 study by Ahmed et al, reserpinated mice showed a significant decrease in rearing and grooming behavior as well as motor activity (25). As can be seen, the findings of the above studies confirm our results.

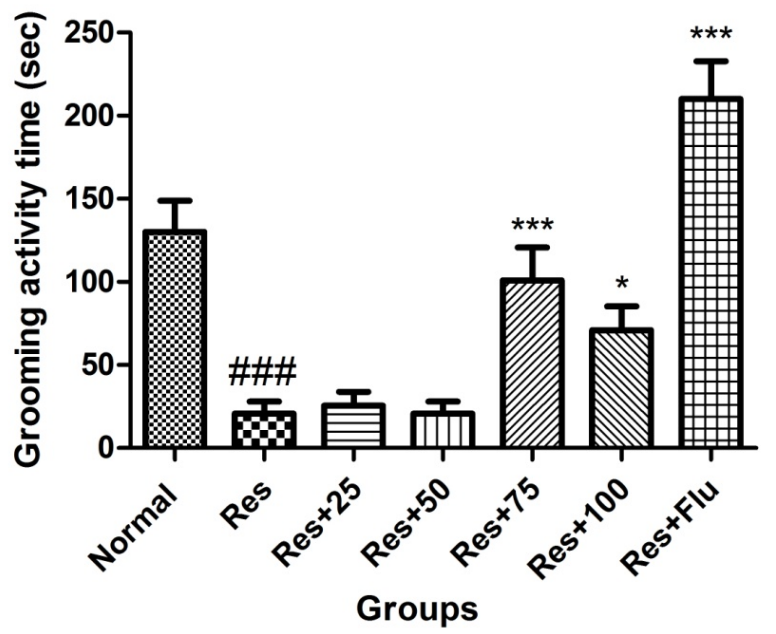

Figure 3. The effect of intraperitoneal injection of four different concentrations of Kelussia odoratissima Mozaffarian extract (25, 50, 75 and $100 \mathrm{mg} / \mathrm{kg}$ ) on the licking time of mice. Flu= Fluoxetine, Res=reserpine. ${ }^{*}$ Vs. normal group $\left({ }^{\sharp \# *} P<0.001{ }^{*} V\right.$ s. reserpinereceiving group $\left({ }^{*} P<0.05,{ }^{* * *} P<0.001\right)$. 

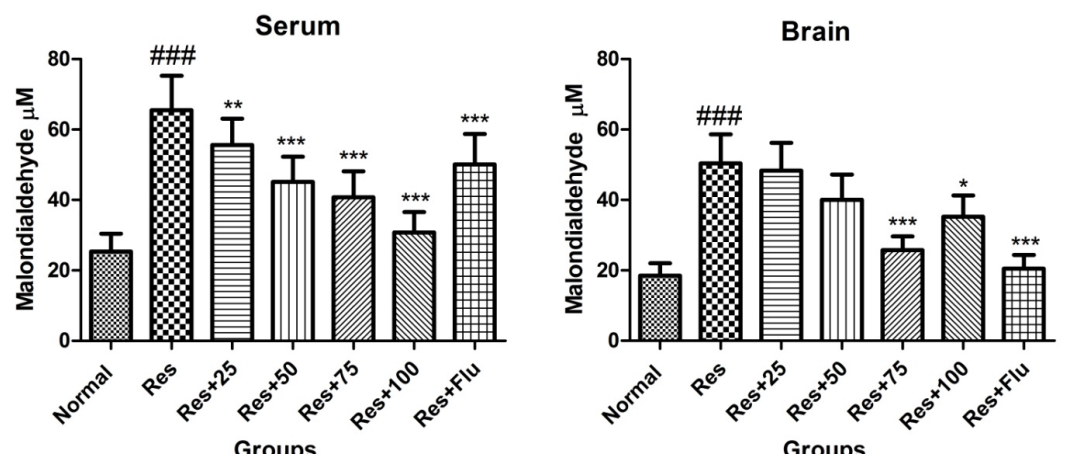

Figure 4. The effect of intraperitoneal injection of different concentrations of Kelussia odoratissima Mozaffarian extract (25, 50, 75, and $100 \mathrm{mg} / \mathrm{kg})$ on the brain and serum MDA levels of mice. Flu= Fluoxetine, Res=reserpine. ${ }^{*}$ Vs. normal group $\left({ }^{\sharp \sharp *} P<0.001\right),{ }^{* * * *} P<0.001{ }^{*} \mathrm{Vs}$. reserpine-receiving group $\left({ }^{*} P<0.05,{ }^{* *} P<0.01\right)$.

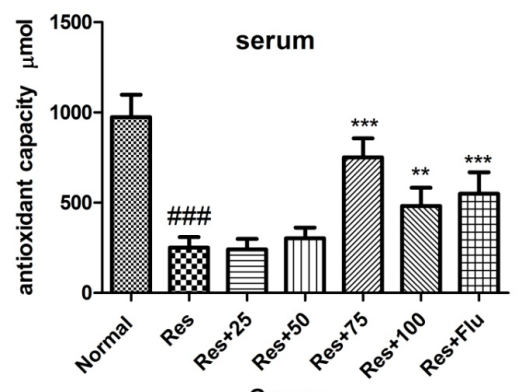

Groups

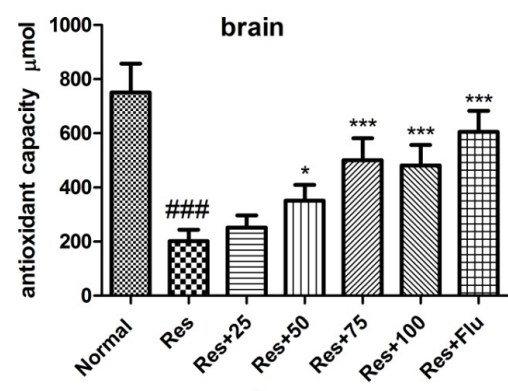

Groups

Figure 5. Effects of intraperitoneal injection of four different concentrations of Kelussia odoratissima Mozaffarian extract (25, 50, 75, and 100 $\mathrm{mg} / \mathrm{kg}$ ) on serum and brain antioxidant capacity in mice. Flu= Fluoxetine, Res=reserpine. "Vs. normal group $\left({ }^{\sharp \sharp} P<0.001\right)$, "Vs. compared with the reserpine-receiving group $\left({ }^{*} P<0.05,{ }^{* *} P<0.01,{ }^{* * *} P<0.001\right)$.

In the present study, treatment of reserpine-receiving mice with $25,50,75$, and $100 \mathrm{mg} / \mathrm{kg}$ of $K$. odoratissima extract was significantly associated with improvement of quasi-depressive behaviors in the forced swim test, represented by reduced duration of immobility.

The $K$. odoratissima extract at doses of 50,75, and 100 $\mathrm{mg} / \mathrm{kg}$ caused a significant increase in rearing behavior, and at 75 and $100 \mathrm{mg} / \mathrm{kg}$ caused a significant increase in grooming behavior, which indicates the antidepressant effects of plant extract. As far as the researchers investigated, no study has yet been conducted on the antidepressant effects of hydroalcoholic extract of $K$. odoratissima.

However, the anxiolytic and sedative effects of $K$. odoratissima extract were investigated by Rabbani et al. They observed that 75 and $100 \mathrm{mg} / \mathrm{kg}$ of the extract had no significant effect on animal behavior in the elevated plus maze, but it showed sedative effects in the rotarod test (15).

In a 2011 study by Arora et al, it was reported that the induction of depression by reserpine in rats significantly increased the oxidative and nitrosative stress markers (26). In other animal models of depression such as depression induced by unpredictable chronic stress (27), depression induced by separation from the mother (28), depression induced by corticosteroid injections (29), and depression induced by chronic immobilized stress (30), oxidative stress parameters have been reported to increase, which confirm our findings.

Studies have also reported some degree of oxidative stress in people with depressive disorders. For example, in a study in Tehran, Iran on women with postpartum depression, the serum antioxidant capacity was significantly lower in depressed women than in healthy controls (31). The study conducted by Sarandol et al also showed that in patients with MDD, serum MDA levels increased compared with healthy individuals and total serum antioxidant capacity decreased (32). In the present study, doses of 75 and 100 $\mathrm{mg} / \mathrm{kg}$ of mountain celery extract enhanced antioxidant capacity and reduced MDA in the brain and serum of reserpine mice. So far, the antioxidant effects of celery extract have been proven in a number of studies.

In a 2017 study by Safaeian et al, the effects of hydroalcoholic extract of $K$. odoratissima aerial parts on blood pressure and dexamethasone-induced oxidative stress in male Wistar rats were investigated and it was observed that treatment of dexamethasone-receiving mice with $K$. odoratissima extract $(100,200$, and $400 \mathrm{mg} / \mathrm{kg}$ ) reduces plasma concentrations of hydroperoxides (33). In vitro, the antioxidant activity of the plant's methanolic extract has been studied using beta-carotene bleaching, reducing activity, accelerated oxidation of sunflower oil by thiocyanate and inhibition of DPPH radicals, and has 
been reported to be effective in some studies (17,34).

In general, in the present study, $K$. odoratissima extract exhibited antidepressant effects in reserpinated mice by boosting the antioxidant defense system and reducing oxidative stress marker. However, other mechanisms such as modulation of the hypothalamic-pituitary-adrenal axis, reduction of neural inflammation, and altered levels of monoamines may also be involved in the antidepressant effects of $K$. odoratissima extract, which are suggested to be considered in future studies.

In the present study, it was observed that fluoxetine treatment in mice receiving reserpine significantly reduced MDA and significantly increased serum and brain antioxidant capacity. In a 2009 study by Zafir et al, treatment of mice under chronic stress with fluoxetine, imipramine, and venlafaxine significantly improved behaviors associated with depression, associated with significant increases in the activity of antioxidant enzymes catalase, superoxide dismutase, glutathione peroxidase, and glutathione reductase (35).

\section{Conclusion}

According to the results of the present study, the treatment of reserpinated mice with $K$. odoratissima was associated with a reduction in quasi-depressive behaviors in forced swimming and open-plate tests. K. odoratissima extract also boosted antioxidant capacity and reduced MDA in the brain and serum in resinous mice. Dose $75 \mathrm{mg} / \mathrm{kg}$ of $K$. odoratissima was the best response in this study. The antidepressant activity of mountain celery extract seems to be due to its antioxidant activity of this plant.

Conflict of Interests

The authors declare that there is no conflict of interests.

\section{Ethical Approval}

The study followed the Helsinki Protocol, and was approved by the Ethics Committee of the Shahrekord University of Medical Sciences (approval number: IR.SKUMS.REC.1395.319).

\section{Authors Contribution}

In this study, NA, ZL, MM and FH participated in the design and implementation of the project and HAK and MM helped me in writing the article.

\section{Funding/Support}

This project was implemented with the financial support of the Vice Chancellor for Research of Shahrekord University of Medical Sciences.

\section{Acknowledgments}

This article was derived from a research project approved by the Research and Technology Deputy of the Shahrekord University of Medical Sciences, Iran (approval no. 2347).

\section{References}

1. Dozois DJ, Westra HA. The nature of anxiety and depression: implications for prevention. In: Dozois DJ, Dobson KS, eds. The Prevention of Anxiety and Depression: Theory, Research, and Practice. American Psychological Association; 2014. p. 9-41. doi: 10.1037/10722-002.

2. Nolen-Hoeksema S, Morrow J. A prospective study of depression and posttraumatic stress symptoms after a natural disaster: the 1989 Loma Prieta Earthquake. J Pers Soc Psychol. 1991;61(1):115-21. doi: 10.1037//0022-3514.61.1.115.

3. Bergman J, Miodownik C, Bersudsky Y, Sokolik S, Lerner PP, Kreinin A, et al. Curcumin as an add-on to antidepressive treatment: a randomized, double-blind, placebo-controlled, pilot clinical study. Clin Neuropharmacol. 2013;36(3):73-7. doi: 10.1097/WNF.0b013e31828ef969.

4. Brichenko VS, Kupriyanova IE, Skorokhodova TF. The use of herbal adaptogens together with tricyclic antidepressants in patients with psychogenic depressions. Modern Problems of Pharmacology and Search for New Medicines. 1986;2:58-60.

5. Chang SM, Chen $\mathrm{CH}$. Effects of an intervention with drinking chamomile tea on sleep quality and depression in sleep disturbed postnatal women: a randomized controlled trial. J Adv Nurs. 2016;72(2):306-15. doi: 10.1111/jan.12836.

6. Chen Y, Han T, Qin L, Rui Y, Zheng H. [Effect of total triterpenes from Centella asiatica on the depression behavior and concentration of amino acid in forced swimming mice]. Zhong Yao Cai. 2003;26(12):870-3.

7. Cioanca O, Hritcu L, Mihasan M, Trifan A, Hancianu M. Inhalation of coriander volatile oil increased anxiolyticantidepressant-like behaviors and decreased oxidative status in beta-amyloid (1-42) rat model of Alzheimer's disease. Physiol Behav. 2014;131:68-74. doi: 10.1016/j.physbeh.2014.04.021.

8. Cohen AJ, Bartlik B. Ginkgo biloba for antidepressant-induced sexual dysfunction. J Sex Marital Ther. 1998;24(2):139-43. doi: 10.1080/00926239808404927.

9. Nabavizadeh Rafsanjani F, Shahrani M, Vahedian Ardakani Z, Vahedian Ardakani M. Marjoram increases basal gastric acid and pepsin secretions in rat. Phytother Res. 2007;21(11):10368. doi: 10.1002/ptr.2203.

10. Quan Y, Jin L, Luo K, Jin J, Lim SW, Shin YJ, et al. Assessment of nephrotoxicity of herbal medicine containing aristolochic acid in mice. Korean J Intern Med. 2020;35(2):400-7. doi: 10.3904/kjim.2018.280.

11. Arifah SN, Atho'illah MF, Lukiati B, Lestari SR. Herbal medicine from single clove garlic oil extract ameliorates hepatic steatosis and oxidative status in high fat diet mice. Malays J Med Sci. 2020;27(1):46-56. doi: 10.21315/mjms2020.27.1.5.

12. Omidbaigi R, Sefidkon F, Saeedi K. Essential oil content and composition of Kelussia odoratissima Mozaff. as an Iranian endemic plant. J Essent Oil Bear Plants. 2008;11(6):594-7. doi: 10.1080/0972060x.2008.10643672.

13. Shahrani M, Rafian M, Pilevarian A, Shirzad H, Hashemzadeh $M$, Yosefi $H$. Effect of methanolic extract of Kelussia odoratissima Mozaff. On secretion of stomach acid and pepsin in Wistar rats. J Shahrekord Univ Med Sci. 2007;8(4):88-95.

14. Asgary S, Naderi G, Dashti G, Paknahad Z. Effect of Amirkabiria odorastissima mozaffarian on the development and progression of fatty streaks in hypercholesterolemic rabbits. Phytother Res. 2004;18(5):370-2. doi: 10.1002/ ptr.1423.

15. Rabbani M, Sajjadi SE, Sadeghi M. Chemical composition of the essential oil from kelussia odoratissima Mozaff. and the evaluation of its sedative and anxiolytic effects in mice. Clinics (Sao Paulo). 2011;66(5):843-8. doi: 10.1590/s180759322011000500022.

16. Rogani M, Baluch Nejad T, Ramezani M. Evaluation of chronic oral administration effect of aerial part of Kelussia odoratissima Mozaff. On learning and memory in diabetic Wistar rats. J Med Plants. 2008;7(25):98-105. 
17. Ahmadi F, Kadivar M, Shahedi M. Antioxidant activity of Kelussia odoratissima Mozaff. in model and food systems. Food Chem. 2007;105(1):57-64. doi: 10.1016/j. foodchem.2007.03.056.

18. Wang Z, He Z, Emara AM, Gan X, Li H. Effects of malondialdehyde as a byproduct of lipid oxidation on protein oxidation in rabbit meat. Food Chem. 2019;288:405-12. doi: 10.1016/j.foodchem.2019.02.126.

19. Petit-Demouliere B, Chenu F, Bourin M. Forced swimming test in mice: a review of antidepressant activity. Psychopharmacology (Berl). 2005;177(3):245-55. doi: 10.1007/s00213-004-2048-7.

20. Potdar VH, Kibile SJ. Evaluation of antidepressant-like effect of Citrus maxima leaves in animal models of depression. Iran J Basic Med Sci. 2011;14(5):478-83.

21. Prut $\mathrm{L}$, Belzung $\mathrm{C}$. The open field as a paradigm to measure the effects of drugs on anxiety-like behaviors: a review. Eur J Pharmacol. 2003;463(1-3):3-33. doi: 10.1016/s00142999(03)01272-x.

22. Whishaw IQ, Gharbawie OA, Clark BJ, Lehmann H. The exploratory behavior of rats in an open environment optimizes security. Behav Brain Res. 2006;171(2):230-9. doi: 10.1016/j. bbr.2006.03.037.

23. Emamghoreishi M, Ghasemi F. The effect of subchronic administration of the aqueous and hydro-alcoholic extracts of crocus sativus from Estahbanat, Fars province, on mice. Armaghane Danesh. 2012;16(6):527-36. [Persian].

24. Angrini M, Leslie JC, Shephard RA. Effects of propranolol, buspirone, pCPA, reserpine, and chlordiazepoxide on openfield behavior. Pharmacol Biochem Behav. 1998;59(2):38797. doi: 10.1016/s0091-3057(97)00457-7.

25. Ahmed RF, Abdel-Rahman RF, Abdallah H, Saleh DO, Farid OA, Hessin AF. Antidepressant-like effect of resveratrol in a subchronic model of depression. J Arab Soc Med Res. 2014;9(2):48-53. doi: 10.4103/1687-4293.145619.

26. Arora V, Kuhad A, Tiwari V, Chopra K. Curcumin ameliorates reserpine-induced pain-depression dyad: behavioural, biochemical, neurochemical and molecular evidences. Psychoneuroendocrinology. 2011;36(10):1570-81. doi: 10.1016/j.psyneuen.2011.04.012.
27. Moretti M, Colla A, de Oliveira Balen G, dos Santos DB, Budni J, de Freitas AE, et al. Ascorbic acid treatment, similarly to fluoxetine, reverses depressive-like behavior and brain oxidative damage induced by chronic unpredictable stress. J Psychiatr Res. 2012;46(3):331-40. doi: 10.1016/j. jpsychires.2011.11.009.

28. Schiavone S, Jaquet V, Trabace L, Krause KH. Severe life stress and oxidative stress in the brain: from animal models to human pathology. Antioxid Redox Signal. 2013;18(12):147590. doi: 10.1089/ars.2012.4720.

29. Gupta D, Radhakrishnan M, Kurhe Y. Effect of a novel 5-HT3 receptor antagonist $4 \mathrm{i}$, in corticosterone-induced depressionlike behavior and oxidative stress in mice. Steroids. 2015;96:95-102. doi: 10.1016/j.steroids.2015.01.021.

30. Zafir A, Banu N. Modulation of in vivo oxidative status by exogenous corticosterone and restraint stress in rats. Stress. 2009;12(2):167-77. doi: 10.1080/10253890802234168.

31. Ranjbaran M, Sadeghipour Roudsari HR, Nikseresht S, Etebary S. Antioxidant status and endocannabinoid concentration in postpartum depressive women. Tehran Univ Med J. 2015;72(11):773-9.

32. Sarandol A, Sarandol E, Eker SS, Erdinc S, Vatansever E, Kirli S. Major depressive disorder is accompanied with oxidative stress: short-term antidepressant treatment does not alter oxidative-antioxidative systems. Hum Psychopharmacol. 2007;22(2):67-73. doi: 10.1002/hup.829.

33. Safaeian L, Sajjadi SE, Haghjoo Javanmard S, Gholamzadeh $\mathrm{H}$. Antihypertensive and antioxidant effects of hydroalcoholic extract from the aerial parts of Kelussia odoratissima Mozaff. in dexamethasone-induced hypertensive rats. Adv Biomed Res. 2016;5:25. doi: 10.4103/2277-9175.176342.

34. Saeedi KA, Omidbaigi R. Evaluation of content and composition of fatty acids, total phenolic and essential oil content of Kelussia odoratissima Mozaff. seed. Iran J Med Aromat Plants. 2009;25(1):113-9.

35. Zafir A, Ara A, Banu N. In vivo antioxidant status: a putative target of antidepressant action. Prog Neuropsychopharmacol Biol Psychiatry. 2009;33(2):220-8. doi: 10.1016/j. pnpbp.2008.11.010. 